Article

\title{
The Improvement of Hardness and Corrosion Resistance of Electroplated Pd-Ni Film on 316L Stainless Steel by $\mathrm{CeCl}_{3}$
}

\author{
Guangxin Wang, Dongdong Li, Yu Zuo, Yuming Tang *, Xiaofeng Zhang and Xuhui Zhao * \\ Beijing Key Laboratory of Electrochemical Process and Technology for Materials, Beijing University of Chemical \\ Technology, Beijing 100029, China; gxwang1996@163.com (G.W.); superleedommax@163.com (D.L.); \\ zuoy@mail.buct.edu.cn (Y.Z.); zhangxf@mail.buct.edu.cn (X.Z.) \\ * Correspondence: tangym@mail.buct.edu.cn (Y.T.); xhzhao@mail.buct.edu.cn (X.Z.)
}

Received: 26 December 2019; Accepted: 6 February 2020; Published: 10 February 2020

\begin{abstract}
By using the methods of XRD, SEM/EDS, electrochemical polarization, and a weight loss test, the effects of the rare earth salt $\mathrm{CeCl}_{3}$ on the adherence, hardness, porosity and corrosion resistance of an electroplated Pd-Ni film on 316L stainless steel were studied. The results showed that by adding $1.0 \mathrm{~g} \mathrm{~L}^{-1} \mathrm{CeCl}_{3}$ in the plating bath, the obtained Pd-Ni film was obviously improved. The grain size was refined, and the microstructure was more compact and uniform. The film hardness and the adherence to the substrate increased, and the corrosion resistance in a $20 \mathrm{wt} \% \mathrm{H}_{2} \mathrm{SO}_{4}$ solution $\left(80{ }^{\circ} \mathrm{C}\right)$ obviously increased. $\mathrm{Ce}^{3+}$ increased the throwing power of the bath, which resulted in more uniform current distribution and strengthened the cathodic polarization degree during the electroplating process.
\end{abstract}

Keywords: Pd-Ni film; electroplating; $\mathrm{CeCl}_{3}$; corrosion resistance; grain size; throwing power

\section{Introduction}

The rare earths have been used in many fields such as electroplating, surface conversion coating, heat treatment, metal corrosion protection, and friction resistance, which makes them good prospects for applications [1-6] due to their unique electronic structures and chemical activity. Electroplating is a traditional surface protection technology. In the electroplating process, adding a small amount of soluble rare earth salt in the plating bath can improve the properties of the coatings, such as some physical properties and corrosion resistance [1,3,4] In addition, a rare earth salt can improve the throwing power (T.P.) of the plating solution, reduce the grain size of the plating alloy, and make the microstructure of the coating more uniform [7-9]. The T.P. is a measure of an electroplating solution's ability to plate a uniform film over an irregularly shaped cathode, which can be evaluated by using a Haring-Blum rectangular cell. Under the same plating conditions, the larger the T.P. value, the stronger throwing power of the electroplating solution and the more uniform the film formed on the surface of the substrate [9].

The palladium film has excellent corrosion resistance, abrasive resistance, electrical conductivity, catalytic properties, hydrogen evolution performance, and a white appearance, all of which have led to its use as good hydrogen storage and catalytic materials. It has also been widely used in the electronics industry, in applications such as semiconductors and printed circuit boards, and the decorative industry $[10,11]$. In our previous study, Pd film plating on stainless steel was shown to greatly improve corrosion resistance in strong reductive corrosive environments, such as a hot, diluted sulfuric solution, by effectively improving the passive ability of the steel [12]. Pd-Ni and Pd-Cu alloy coatings with good surface micro-hardness and adhesive strength were deposited on 316 L stainless steel by electroplating, and these coatings showed very good corrosion resistance in a hot sulfuric acid solution and an acetic 
solution $[13,14]$. Compared with pure Pd film, a Pd alloy film can reduce the cost of the electroplating. Though previous researchers have studied the influence of rare earths on some electrodeposited coatings, most of them have been applied to the process of chromium, nickel, copper, iron and their alloy plating. There have been few reports that have focused on the role of rare earth compounds in $\mathrm{Pd}$ alloy electroplating $[1-3,7,8]$. In order to further improve the performance of Pd-Ni alloy coating and understand the effects of rare earth metals on the electroplating process of $\mathrm{Pd}-\mathrm{Ni}$, in this paper, different contents of $\mathrm{CeCl}_{3}$ were introduced in a Pd-Ni basic plating electrolyte; the throwing power of the rare earth on the plating solution was studied, and the main physical properties of the coating such as bonding strength, hardness, porosity, and corrosion resistance in a hot, diluted $\mathrm{H}_{2} \mathrm{SO}_{4}$ solution were investigated by weight loss and polarization tests combined with the XRD and SEM/EDS methods.

\section{Experimental}

\subsection{Sample Preparation}

316L stainless steel with the chemical composition (wt \%) of $16.80 \mathrm{Cr}, 13.50 \mathrm{Ni}, 0.02 \mathrm{C}, 1.40 \mathrm{Mn}$, $0.32 \mathrm{Si}, 0.017 \mathrm{P}, 0.014 \mathrm{~S}, 2.30 \mathrm{Mo}$, and $65.6 \mathrm{Fe}$, was used as substrate and machined to dimensions of $25 \mathrm{~mm} \times 10 \mathrm{~mm} \times 1 \mathrm{~mm}$. Before electroplating, the sample surface was ground with SiC abrasive papers up to $1000^{\#}$ grade and then degreased in an alkali solution at $80^{\circ} \mathrm{C}$ for $30 \mathrm{~min}$. After degreasing, the samples were etched in an acidic solution at $45^{\circ} \mathrm{C}$ for $10 \mathrm{~min}$ at a current density of $20 \mathrm{~A} \mathrm{dm}^{-2}$. Then, the samples were rinsed with deionized water. Finally, the $\mathrm{Pd}-\mathrm{Ni}$ alloy film was deposited on the steel substrate in a basic plating solution $(\mathrm{pH} 8-9)$ at $45{ }^{\circ} \mathrm{C}$ for $5 \mathrm{~min}$ at a current density of $1 \mathrm{~A} \mathrm{dm}^{-2}[13,14]$. During the electroplating process, $0-2 \mathrm{~g} \mathrm{~L}^{-1}$ soluble rare earth salt $\mathrm{CeCl}_{3}$ was added in order to improve the throwing power of the plating solution and the properties of the films. The anode was graphite with a size of $60 \mathrm{~mm} \times 40 \mathrm{~mm} \times 10 \mathrm{~mm}$. The compositions of the alkali solution, the acidic solution, and the basic plating solution are shown in Table 1.

Table 1. Compositions of the alkali solution, the acidic solution, and the basic plating solution.

\begin{tabular}{cccccc}
\hline \multicolumn{2}{c}{ Alkali Solution $\left(\mathrm{g} \mathrm{L}^{\mathbf{- 1}}\right)$} & \multicolumn{2}{c}{ Acidic Solution $\left(\mathbf{g ~ L}^{\mathbf{- 1}}\right)$} & \multicolumn{2}{c}{ Plating Solution $\left(\mathrm{g} \mathrm{L}^{\mathbf{- 1}}\right)$} \\
\hline $\mathrm{Na}_{2} \mathrm{CO}_{3}$ & 40 & $\mathrm{H}_{2} \mathrm{SO}_{4}(98 \%)$ & 180 & $\mathrm{PdCl}_{3}$ & 5.53 \\
$\mathrm{Na}_{3} \mathrm{PO}_{4}$ & 40 & $\left(\mathrm{NH}_{4}\right)_{2} \mathrm{SO}_{4}$ & 80 & $\mathrm{Na}_{3} \mathrm{C}_{6} \mathrm{H}_{5} \mathrm{O}_{7} \cdot 2 \mathrm{H}_{2} \mathrm{O}$ & 45 \\
$\mathrm{NaOH}$ & 25 & & & $\mathrm{NH}_{4} \mathrm{Cl}$ & 75 \\
$\mathrm{NaCl}$ & 25 & & $\mathrm{NH}_{3} \cdot \mathrm{H}_{2} \mathrm{O}$ & 70 \\
& & & & $\mathrm{NiSO}_{4} \cdot 6 \mathrm{H}_{2} \mathrm{O}$ & 30 \\
\hline
\end{tabular}

\subsection{Characterization}

The surface morphology of the plated sample was observed with SEM. The composition of the film was analyzed with EDS. The structure of the film was analyzed with XRD by a 2500VB2+PC diffractometer (Japan) while using $\mathrm{CuK} \mu$ radiation filtered and focusing with a Göbel mirror. The crystallite sizes of the plated film were calculated with the Scherrer equation: $D=0.9 \lambda /(\beta \cos \theta)$, where $D$ is the crystallite size, $\lambda$ is the X-ray wavelength, $\beta$ is the peak width at half height, and $\theta$ is the diffraction angle.

The hardness of the film was measured with an HM2000 micro-hardness tester (Fischer, Germany). The load was $20 \mathrm{mN}$, and the loading time was $20 \mathrm{~s}$. For each sample, ten parallel tests were performed, and the average value was obtained. The adhesive strength between the film and the steel substrate was measured with a PosiTest Pull-off Adhesion Tester (DeFelsko) according to ISO (International Organization for Standardization) 4624-2002. The film porosity was evaluated by a filter paper method according to the standard QB/T (China light industry standard) 3823-1999 (the polarity measuring for metallic coatings).

The corrosion resistance of the Pd-Ni alloy-plated samples in a $20 \mathrm{wt} \% \mathrm{H}_{2} \mathrm{SO}_{4}$ solution at $80{ }^{\circ} \mathrm{C}$ was studied by weight loss $(72 \mathrm{~h})$ and polarization tests. The samples for the polarization test were 
sealed with epoxy resin, leaving an area of $0.5 \mathrm{~cm}^{2}$ exposed to the testing solution. Polarization measurements were carried out with a CS350 electrochemical workstation (CorrTest, China). Before polarization, the sample was first immersed in the solution for $25 \mathrm{~min}$ until a stable open circuit potential (OCP) was obtained, and then polarization was started at a potential of $0.15 \mathrm{~V}$ negative to OCP and ended at a potential $1 \mathrm{~V}$ positive to $\mathrm{OCP}$ with a scanning rate of $0.66 \mathrm{mV} \mathrm{s}^{-1}$. A three-electrode system, in which a saturated calomel electrode (SCE) was the reference electrode and a platinum electrode was the auxiliary electrode, was used.

The throwing power (T.P.) of the electroplating solution was evaluated by using a Haring-Blum rectangular cell. One anode was fixed between two cathodes where the near-to-far distance ratio was 1:3. The T.P.\% was calculated by Formula (1) [9]:

$$
\text { T.P. }=\frac{K-M}{K+M-2} \times 100 \%
$$

where $K$ is the current distribution ration (3:1) and $M$ is the alloy weight distribution ratio (the weight of the alloy deposited on the near cathode divided by the weight of the alloy deposited on the far cathode).

For each condition, five parallel tests were measured, and the average values were obtained.

\section{Results and Discussion}

\subsection{Composition and Microstructure of the Pd-Ni Film}

Figure 1 shows the cross section morphology of the Pd-Ni film that was plated on the stainless steel sample. It could be seen that the thickness of the film was about $2 \mu \mathrm{m}$. The contents of the Pd and $\mathrm{Ni}$ elements in the plated film that were determined by EDS are shown in Table 2. It could be seen that the concentration of $\mathrm{CeCl}_{3}$ had no significant influence on the film's composition. It could be inferred that the effect of $\mathrm{CeCl}_{3}$ on the electrodeposition of $\mathrm{Pd}$ and $\mathrm{Ni}$ was similar. The Ce element was not detected in the Pd-Ni alloy film. This was probably because the electronegativity of the rare earth element $\mathrm{Ce}$ is relatively low and the deposition potential of the rare earth element $\mathrm{Ce}$ is very negative (around $-2.4 \mathrm{~V}$ ), so it is difficult for Ce to be directly deposited [15]. In the electrodeposition process of $\mathrm{Pd}$ and $\mathrm{Ni}$, the cathode potential was higher than the deposition potential of $\mathrm{Ce}$, so Ce could not enter into the Pd-Ni alloy film by a reduction reaction.

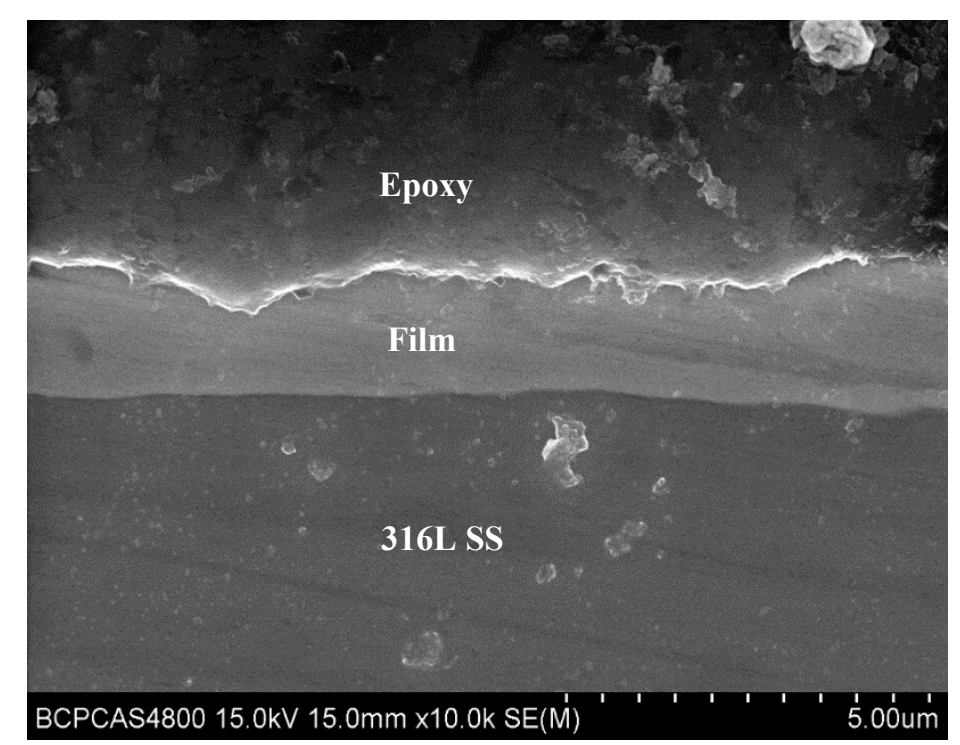

Figure 1. The cross section morphology of the Pd-Ni film. 
Table 2. EDS results for the Pd-Ni alloy film that was electroplated in a solution that contained different concentrations of $\mathrm{CeCl}_{3}$.

\begin{tabular}{ccccccc}
\hline $\mathbf{C e C l}_{\mathbf{3}}\left(\mathrm{g} \mathrm{L}^{\mathbf{- 1}}\right)$ & $\mathbf{0}$ & $\mathbf{0 . 2}$ & $\mathbf{0 . 5}$ & $\mathbf{1 . 0}$ & $\mathbf{1 . 5}$ & $\mathbf{2 . 0}$ \\
\hline $\mathrm{Pd}(\mathrm{at} \%)$ & $55.2 \pm 5.5$ & $57.7 \pm 5.8$ & $54.8 \pm 5.5$ & $55.7 \pm 5.6$ & $55.0 \pm 5.5$ & $55.1 \pm 5.5$ \\
$\mathrm{Ni}(\mathrm{at} \%)$ & $44.8 \pm 4.5$ & $42.3 \pm 4.2$ & $45.2 \pm 4.5$ & $44.3 \pm 4.4$ & $45.0 \pm 4.5$ & $44.9 \pm 4.5$ \\
\hline
\end{tabular}

Figure 2 shows the X-ray diffraction pattern of the Pd-Ni film. The film showed a single phase FCC (Face-centered cubic) structure, indicating that a substitution solid solution formed during the electrodeposition. The addition of $\mathrm{CeCl}_{3}$ did not change the crystal type of the film. It can be seen from Figure 2 that the position of the Pd-Ni diffraction peak is close to but slightly shifted to the right of that of the pure Pd diffraction peak. This is because the lattice constant of $\mathrm{Ni}$ is smaller than that of $\mathrm{Pd}$, and the $\mathrm{Ni}$ atom partially replaces the position of $\mathrm{Pd}$ in crystal, which resulted in the lattice constant of Pd-Ni decreasing compared with that of pure Pd. Table 3 shows the crystallite sizes of the $\mathrm{Pd}$ alloy films, as calculated by Scherrer equation. It can be seen that the crystallite size of the Pd-Ni film was reduced after $\mathrm{CeCl}_{3}$ addition, indicating that the addition of $\mathrm{CeCl}_{3}$ apparently decreased the crystallite size and refined the microstructure of the Pd-Ni film, which is in agreement with the results in the literature [16,17].

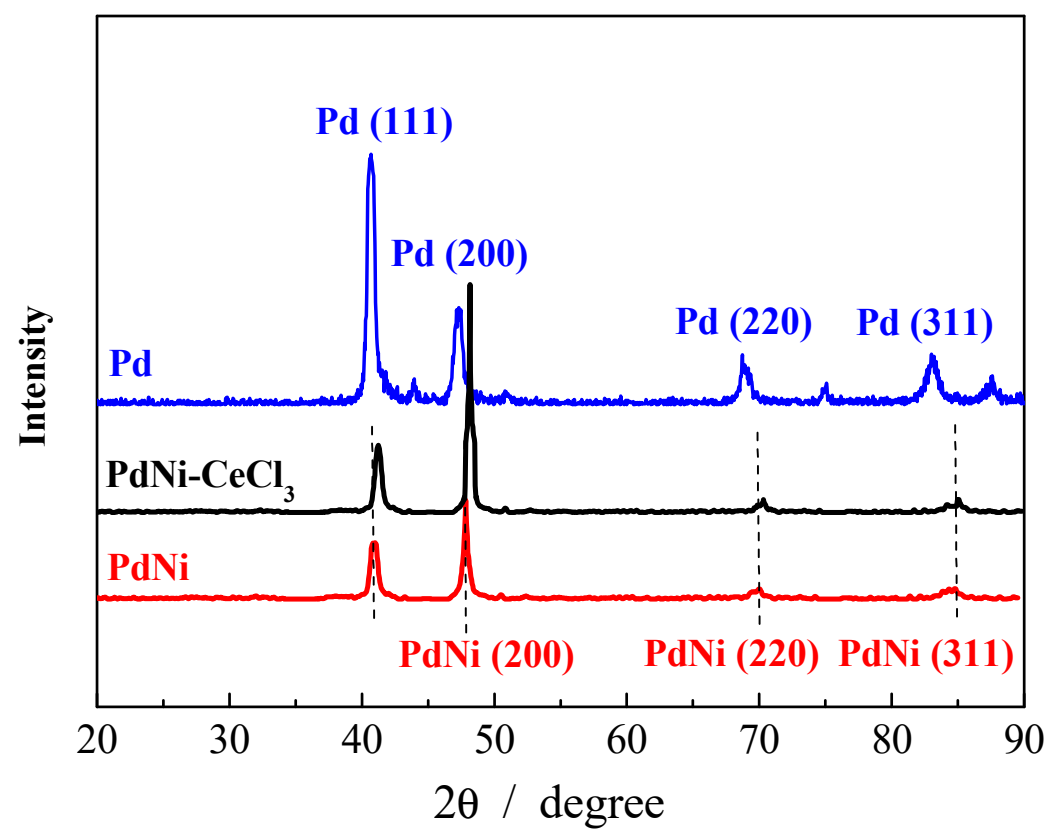

Figure 2. The XRD patterns of the Pd-Ni alloy films.

Table 3. The crystallite sizes of the Pd-Ni alloy films.

\begin{tabular}{ccc}
\hline Sample & Diffraction Angle & Crystallite Size (nm) \\
\hline \multirow{2}{*}{ Pd-Ni film (without $\mathrm{CeCl}_{3}$ ) } & 40.867 & 21.718 \\
& 47.641 & 18.709 \\
\hline \multirow{2}{*}{ Pd-Ni film (with $\mathrm{CeCl}_{3}$ ) } & 41.063 & 17.848 \\
& 47.972 & 15.032 \\
\hline
\end{tabular}

\subsection{Hardness and Adhesion Tests Results}

Figure 3 shows the micro-hardness and adhesive strength of the Pd-Ni alloy film that was obtained in the electrodeposition solutions that contained different concentrations of $\mathrm{CeCl}_{3}$. The hardness of the Pd-Ni film in the solution without $\mathrm{CeCl}_{3}$ was $524 \mathrm{HV}$. After $\mathrm{CeCl}_{3}$ addition, the hardness was 
improved, and it reached its maximum value $(578.7 \mathrm{HV})$ when the $\mathrm{CeCl}_{3}$ concentration was $1.0 \mathrm{~g} \mathrm{~L}^{-1}$. The adhesive strength between the Pd-Ni film and the substrate was also significantly improved after the $\mathrm{CeCl}_{3}$ addition. With the $\mathrm{CeCl}_{3}$ concentration increasing, the adhesive strength firstly increased and then decreased; it achieved a maximum (5.64 MPa) at around $1.0 \mathrm{~g} \mathrm{~L}^{-1}$ of $\mathrm{CeCl}_{3}$ addition in the electroplating solution. This shows that adding proper concentration of $\mathrm{CeCl}_{3}$ can enhance the adhesive strength between a film and a substrate, thereby increase the protective effect of a film to a substrate. It can be noted that the adhesive strength and hardness of the Pd-Ni film had the same variation tendency with the concentration of $\mathrm{CeCl}_{3}$ in the plating solution. This was probably because that the addition of cerium salt could refine the film's grain size, reduce the film's pinholes during deposition, and make the surface of the film more compact and uniform [16,17]. These would have resulted in an enhanced bonding force [16]. Meanwhile, according to the Hall-Petch relationship, the micro-hardness of the film was also improved as the result of the grain refinement [18,19]. However, the excessive addition of cerium salt could have degraded the homogeneity of the film, which resulted in the decrease of the hardness and the adhesive force of the film. This is in agreement with the results of some of the literature $[16,17]$.

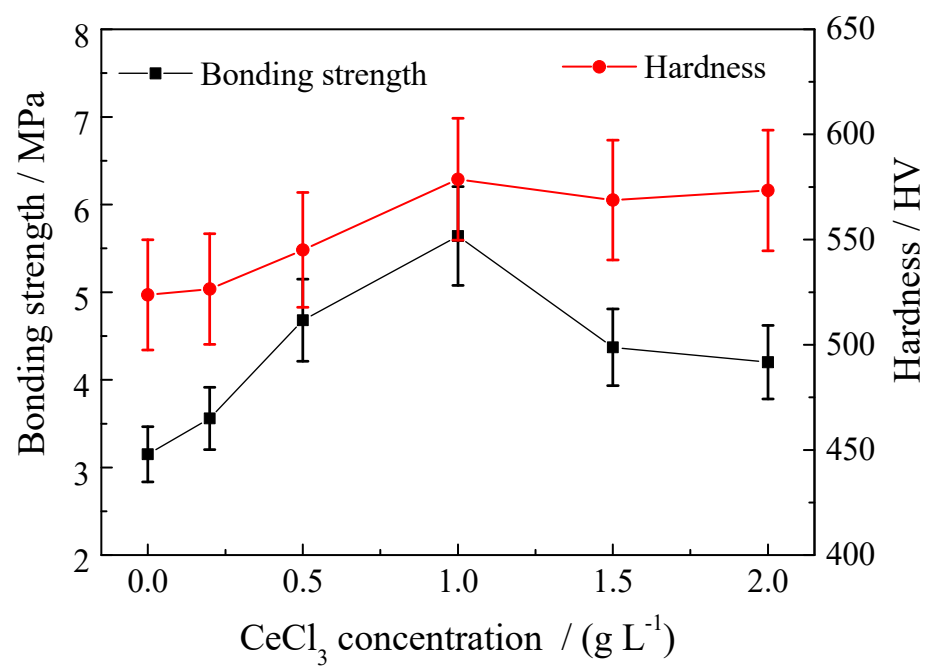

Figure 3. The micro-hardness and adhesive strength of the Pd-Ni alloy film that was obtained at different contents of $\mathrm{CeCl}_{3}$ in the electroplating solution.

\subsection{Porosity of the Pd-Ni Alloy Films}

Porosity is one of the key indicators of the quality of a film. Table 4 shows the porosity of the Pd-Ni alloy films that were obtained in the solutions with different concentrations of $\mathrm{CeCl}_{3}$. Compared with the Pd-Ni film without $\mathrm{CeCl}_{3}$ addition, the film after adding 1.0 and $1.5 \mathrm{~g} \mathrm{~L}^{-1}$ of $\mathrm{CeCl}_{3}$ had a lower porosity. According to the literature, porosity is formed mainly due to the hydrogen evolution occurring on the surface of a substrate $[3,16]$. When hydrogen generation is suppressed, porosity can be significantly reduced. The adsorption of cerium ions on the surface enhanced the reduction potential of $\mathrm{H}^{+}$and inhibited the adsorption of hydrogen ions. Therefore, it was more difficult for $\mathrm{H}^{+}$ to be reduced, and the reaction rate of hydrogen evolution thereby decreased, so the occurrence of pinholes in the film was inhibited to some degree [20]. The trend of the porosity with the variation of the cerium salt concentration was similar to that in the literature [16].

Table 4. Porosity of the Pd-Ni alloy films that were obtained in the solutions with different contents of $\mathrm{CeCl}_{3}$.

\begin{tabular}{ccccccc}
\hline $\mathrm{CeCl}_{\mathbf{3}}\left(\mathrm{g} \mathrm{L}^{-1}\right)$ & $\mathbf{0}$ & $\mathbf{0 . 2}$ & $\mathbf{0 . 5}$ & $\mathbf{1 . 0}$ & $\mathbf{1 . 5}$ & $\mathbf{2 . 0}$ \\
\hline Porosity $\left(\mathrm{cm}^{-2}\right)$ & 1 & 1 & 1 & 0.5 & 0.5 & 1 \\
\hline
\end{tabular}




\subsection{Weight Loss Tests}

Weight loss tests were carried out for electroplated steel samples in a $20 \mathrm{wt} \% \mathrm{H}_{2} \mathrm{SO}_{4}$ solution at $80^{\circ} \mathrm{C}$. After immersion for $72 \mathrm{~h}$, apparent corrosion was observed on the Pd-Ni film that was obtained in the plating solution without $\mathrm{CeCl}_{3}$, and part of the film was peeled off from the steel substrate. After the addition of $\mathrm{CeCl}_{3}$, the adhesive force and the corrosion resistance of the film were enhanced. Table 5 shows the corrosion rate of the Pd-Ni film in the $20 \mathrm{wt} \% \mathrm{H}_{2} \mathrm{SO}_{4}$ solution $\left(80^{\circ} \mathrm{C}\right)$, as calculated from weight loss test. With the increase of the content of $\mathrm{CeCl}_{3}$ in the plating solution, the corrosion rate first decreased and then slightly increased. The lowest corrosion rate, which was $0.0039 \mathrm{~g} \mathrm{~m}^{-2} \mathrm{~h}^{-1}$, was obtained when the content of $\mathrm{CeCl}_{3}$ was $1.0 \mathrm{~g} \mathrm{~L}^{-1}$, and, after $72 \mathrm{~h}$ of immersion, the surface film was intact.

Table 5. Corrosion rate of the Pd-Ni Film in a $20 \mathrm{wt} \% \mathrm{H}_{2} \mathrm{SO}_{4}$ solution at $80{ }^{\circ} \mathrm{C}$ from weight loss tests.

\begin{tabular}{ccccccc}
\hline $\mathrm{CeCl}_{\mathbf{3}}$ content $\left(\mathrm{g} \mathrm{L}^{-\mathbf{1}}\right)$ & $\mathbf{0}$ & $\mathbf{0 . 2}$ & $\mathbf{0 . 5}$ & $\mathbf{1 . 0}$ & $\mathbf{1 . 5}$ & $\mathbf{2 . 0}$ \\
\hline Corrosion rate $\left(\mathrm{g} \mathrm{m}^{-2} \mathrm{~h}^{-1}\right)$ & 0.1038 & 0.065 & 0.0054 & 0.0039 & 0.0045 & 0.0069 \\
\hline
\end{tabular}

Figure 4 shows the potentiodynamic polarization curves performed in the $20 \mathrm{wt} \% \mathrm{H}_{2} \mathrm{SO}_{4}$ solution $\left(80^{\circ} \mathrm{C}\right)$. The corrosion current density $\left(i_{\mathrm{c}}\right)$ and corrosion potential $\left(E_{\mathrm{c}}\right)$ of the electroplated sample were obtained from polarization curves and are shown in Table 6. It can be seen that the corrosion potentials of the samples with the Pd-Ni film ranged between 0.18 and $0.27 \mathrm{~V}$, which was in the passive range of the $316 \mathrm{~L}$ stainless steel in the $20 \mathrm{wt} \% \mathrm{H}_{2} \mathrm{SO}_{4}$ solution at $80{ }^{\circ} \mathrm{C}[12,21]$, so electroplating an Pd-Ni alloy film can increase the corrosion potential of stainless steel, thereby maintaining its passivation state and present good corrosion resistance. After $\mathrm{CeCl}_{3}$ addition, the corrosion current density of the electroplated samples decreased. At the $\mathrm{CeCl}_{3}$ content of $1.0 \mathrm{~g} \mathrm{~L}^{-1}$, the corrosion current density reached the lowest value $\left(1.01 \times 10^{-5} \mathrm{~A} \mathrm{dm}^{-2}\right)$, which was consistent with result of the weight loss test.

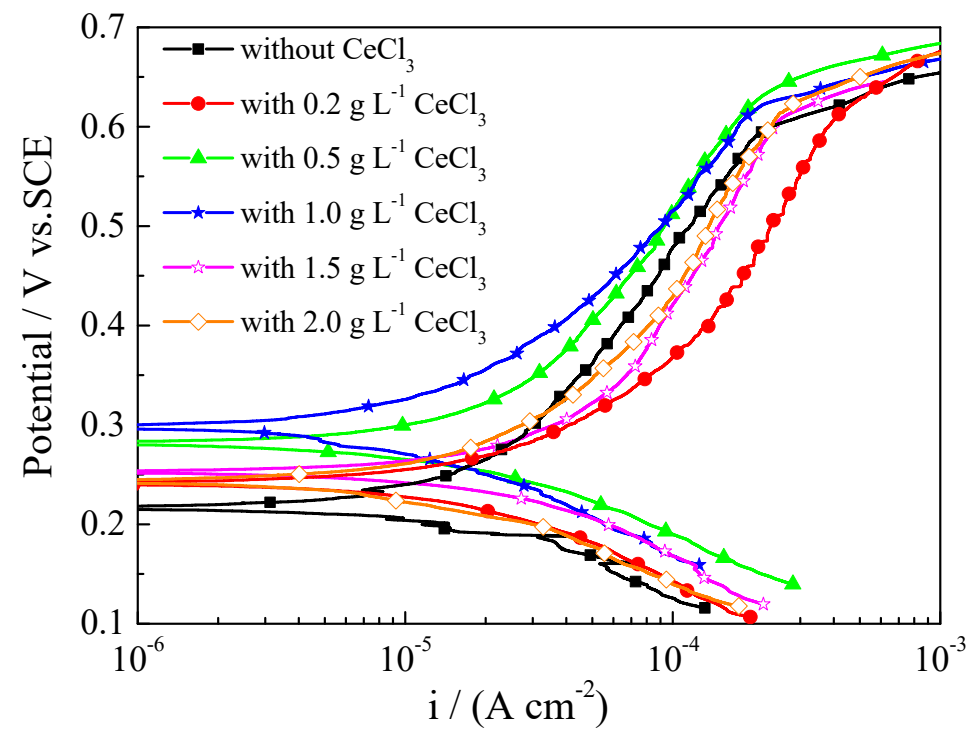

Figure 4. Polarization curves of the plated samples in the solutions with different contents of $\mathrm{CeCl}_{3}$.

Table 6. The corrosion current density $\left(i_{\mathrm{c}}\right)$ and Corrosion Potential $\left(E_{\mathrm{c}}\right)$ of the electroplated samples that were obtained from polarization curves.

\begin{tabular}{ccccccc}
\hline $\mathrm{CeCl}_{\mathbf{3}}\left(\mathrm{g} \mathrm{L}^{-\mathbf{1}}\right)$ & $\mathbf{0}$ & $\mathbf{0 . 2}$ & $\mathbf{0 . 5}$ & $\mathbf{1 . 0}$ & $\mathbf{1 . 5}$ & $\mathbf{2 . 0}$ \\
\hline$i_{c} \times 10^{-5}\left(\mathrm{~A} \mathrm{~cm}^{-2}\right)$ & 2.18 & 1.89 & 1.68 & 1.01 & 2.36 & 2.03 \\
$E_{\mathrm{c}}(\mathrm{V}$ vs. SCE $)$ & 0.21 & 0.18 & 0.26 & 0.27 & 0.22 & 0.19 \\
\hline
\end{tabular}




\subsection{The Morphology of the Pd-Ni Films}

From the above test results, it can be noted that the Pd-Ni film that was deposited in the solution when the $\mathrm{CeCl}_{3}$ content was $1.0 \mathrm{~g} \mathrm{~L}^{-1}$ presented better performances. The surface morphology of the Pd-Ni film was observed by SEM and is shown in Figure 5, where it is compared with the morphology of the film in the solution without $\mathrm{CeCl}_{3}$. It could be seen that after $1.0 \mathrm{~g} \mathrm{~L}^{-1} \mathrm{CeCl}_{3}$ was added, the surface of the Pd-Ni film was more homogeneous and continuous, with less rough particles covered on the surface. As we know, the process of electroplating mainly comprises the absorption and the reduction of cations on the surface of the cathode. Cerium is a surface active element with a large atomic radium $(0.1824 \mathrm{~nm})$, a unique $4 \mathrm{f}$ electron configuration, and a strong adsorption ability. When $\mathrm{CeCl}_{3}$ is added to a plating solution, $\mathrm{Ce}^{3+}$ is preferentially adsorbed on the crystal defects of the cathode and obstructs the reduction of metal cations on the cathode surface [17]; this needs a high cathodic potential to supply the reduction energy of $\mathrm{Pd}\left(\mathrm{NH}_{3}\right)_{2}{ }^{2+}$ and $\mathrm{Ni}\left(\mathrm{NH}_{3}\right)_{2}{ }^{2+}$, so the nucleation rate of the new crystallite is increased and then grains are refined [19].

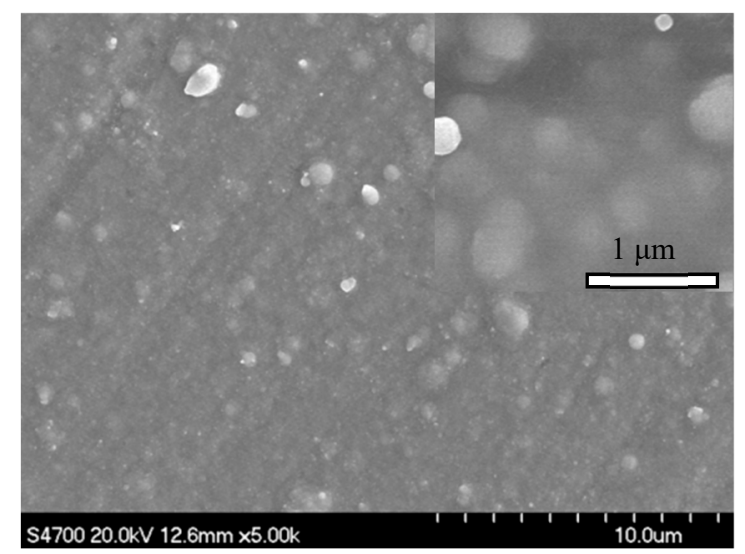

(a)

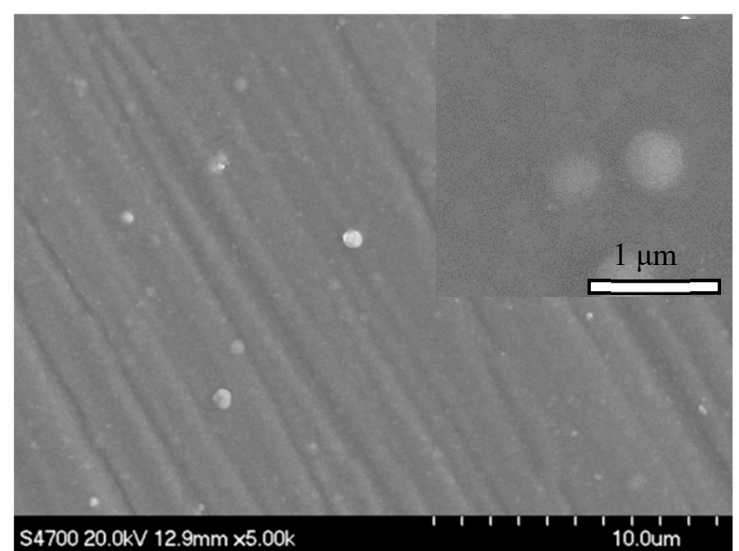

(b)

Figure 5. The surface morphology of the $\mathrm{Pd}-\mathrm{Ni}$ alloy films that were plated in a solution containing different contents of $\mathrm{CeCl}_{3}$ : (a) $0 \mathrm{~g} \mathrm{~L}^{-1} \mathrm{CeCl}_{3}$ and (b) $1 \mathrm{~g} \mathrm{~L}^{-1} \mathrm{CeCl}_{3}$.

\subsection{Throwing Power of the Electroplating Solution}

The throwing power (T.P.) of the electroplating solution was evaluated, and the T.P. value was calculated with Formula (1). The results are shown in Figure 6.

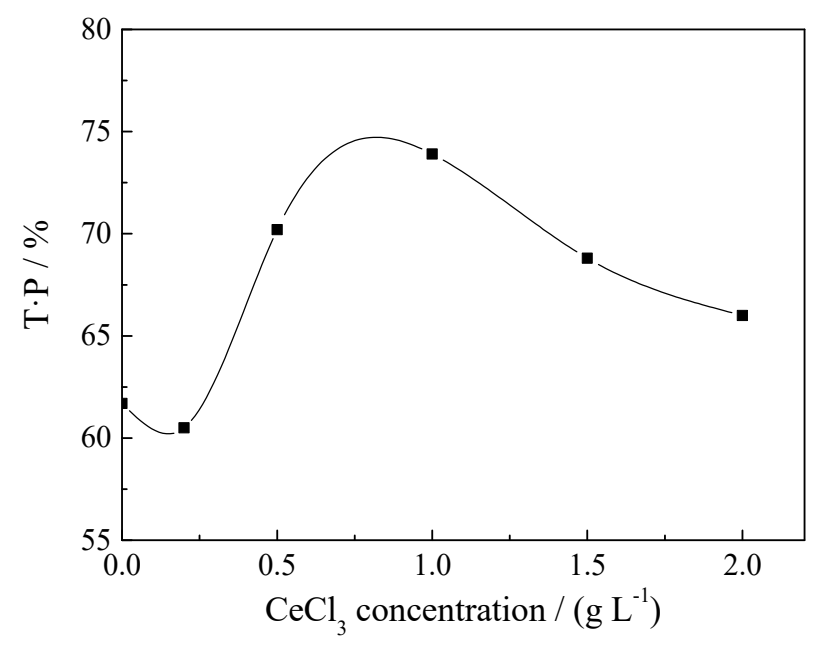

Figure 6. The variation of throwing power (T.P.) values of the plating solutions with $\mathrm{CeCl}_{3}$ concentrations. 
It could be seen that the addition of $\mathrm{CeCl}_{3}$ could improve the throwing power of the bath solution, showing a tendency of first increasing and then decreasing. When the concentration of $\mathrm{CeCl}_{3}$ was $1.0 \mathrm{~g} \mathrm{~L}^{-1}$, the percentage throwing power, T.P.\%, of the plating solution reached $73.9 \%$, which is relatively high [9]. It is supposed that $M\left(m_{1} / m_{2}\right)$ is the weight distribution ration in the base plating bath, and $M^{\prime}\left(m^{\prime}{ }_{1} / m^{\prime}{ }_{2}\right)$ is the weight distribution ration in the plating bath containing $\mathrm{CeCl}_{3}$. Based on the result in Figure 6, it can be inferred that:

$$
M=m_{1} / m_{2}>m^{\prime}{ }_{1} / m^{\prime}{ }_{2}=M^{\prime}
$$

According to the Faraday's law, a relationship exists between the mass of a film $(m)$ and current density (i), as shown in Formula (3), where $t$ is the plating time, $s$ is the sample area, $A$ is the atomic weight, and $F$ is the Faraday constant.

$$
m=i s t A / F
$$

From Formulas (2) and (3), it can be found that:

$$
i_{1} / i_{2}>i^{\prime}{ }_{1} / i^{\prime}{ }_{2}
$$

where $i_{1} / i_{2}$ and $i^{\prime}{ }_{1} / i_{2}^{\prime}$ are the current density ratios of the near and far cathodes in the plating solution without and with $\mathrm{CeCl}_{3}$, respectively. Therefore, the difference between the far and near cathode current densities became smaller after the $\mathrm{CeCl}_{3}$ addition, which means that the distribution of current in the plating solution became more uniform.

There are several factors that affect the near and far cathode current densities $\left(i_{1}\right.$ and $\left.i_{2}\right)$, and these are expressed in Formula (5), where $l_{1}$ is the distance between the near cathode and anode, $\Delta l$ is the distance between the near and far cathodes, $\rho$ is the conductivity of the plating solution, and $\Delta \varphi / \Delta i$ is the degree of cathodic polarization. In the case in which the plating bath structure and the conductivity of the plating solution are basically unchanged, the main factor that affects current distribution is the degree of cathodic polarization. Based on the decrease in the near-far current density ratio after the $\mathrm{CeCl}_{3}$ addition shown in Formula (4), it can be inferred that the cathodic polarization was strengthened because of the rare earth salt addition.

$$
\frac{i_{1}}{i_{2}}=1+\frac{\Delta l}{l_{1}+\frac{1}{\rho} \cdot\left|\frac{\Delta \varphi_{k}}{\Delta i}\right|}
$$

The cathodic polarization curves during the Pd-Ni electrodeposition on the steel substrates were measured, and the results are given in Figure 7. It was observed that the polarization curves were negatively shifted with an increasing rare earth content, indicating that the degree of cathodic polarization improved. However, after the concentration of $\mathrm{CeCl}_{3}$ was higher than $1.0 \mathrm{~g} \mathrm{~L}^{-1}$, the increasing degree of polarization became smaller, probably because the amount of $\mathrm{Ce}^{3+}$ that was absorbed at the cathode approached saturation. The enhanced cathodic polarization indicated that the deposition overpotential was increased. This could have supplied the reduction energy of $\mathrm{Pd}^{2+}$ and $\mathrm{Ni}^{2+}$, consequently accelerating the nucleation rate of the Pd-Ni alloys. As the nucleation rate exceeded the growth rate of crystallites, the crystallization of the alloys was inhibited, resulting in the refinement of the grain size of the alloys and the improvement of the performance of the film [19].

From the above, it can be concluded that $\mathrm{CeCl}_{3}$ improved the properties and played important roles in changing the surface morphology and microstructure of the Pd-Ni alloy films. As for the addition of the cerium salt, the hardness and the adhesive force of the film were increased, and the porosity of the film was decreased. The corrosion resistance of the electroplated stainless steel in the $20 \mathrm{wt} \% \mathrm{H}_{2} \mathrm{SO}_{4}$ solution at $80{ }^{\circ} \mathrm{C}$ was improved. $\mathrm{CeCl}_{3}$ increased the throwing power of the plating bath, so the current distribution was more uniform and the cathodic polarization degree was strengthened during the electroplating process. Consequently, the refinement of grain size and the surface compaction of the alloy film was improved. However, a higher concentration of $\mathrm{CeCl}_{3}$ 
$\left(>1.0 \mathrm{~g} \mathrm{~L}^{-1}\right)$ became deleterious for the electrodepositing film, as manifested by the decrease of the above properties and the corrosion resistance. This is probably because that if too much $\mathrm{Ce}^{3+}$ is adsorbed on the surface of a cathode, the cathodic polarization could become so big that the deposition speed decreases $[17,20]$.

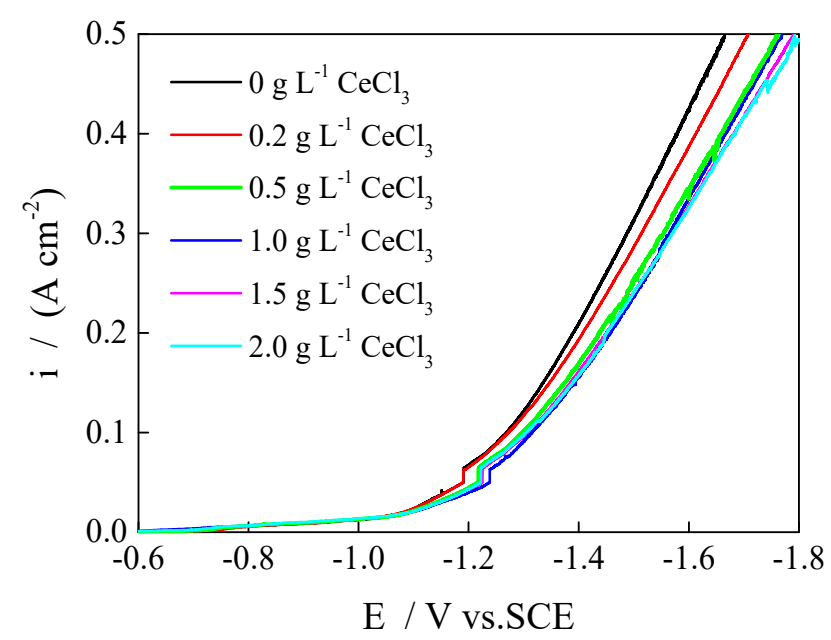

Figure 7. Cathodic polarization curves of the samples in the plating solutions with different concentrations of $\mathrm{CeCl}_{3}$.

\section{Conclusions}

(1) The introduction of $\mathrm{CeCl}_{3}$ to an electroplating solution played important roles in affecting the deposition of a Pd-Ni alloy film on $316 \mathrm{~L}$ stainless steel. The hardness of the Pd-Ni film and its adhesive strength to the stainless steel substrate were improved, the porosity of the film was reduced, and the corrosion resistance of the plated samples in the $20 \mathrm{wt} \% \mathrm{H}_{2} \mathrm{SO}_{4}$ solution at $80^{\circ} \mathrm{C}$ was enhanced.

(2) $\mathrm{CeCl}_{3}$ can improve the throwing power of a plating solution, enhance cathodic polarization during electrodeposition, and promote grain refinement to obtain more compact and uniform films.

(3) The addition of an appropriate amount of $\mathrm{CeCl}_{3}$ into the bath benefited the electrodeposition of the Pd-Ni film. In this study, the optimum addition of $\mathrm{CeCl}_{3}$ was $1.0 \mathrm{~g} \mathrm{~L}^{-1}$. Under this condition, the Pd-Ni film had better performance.

Author Contributions: Data curation, G.W., D.L. and X.Z. (Xuhui Zhao); Funding acquisition, X.Z. (Xuhui Zhao); Investigation, Y.T. and X.Z. (Xiaofeng Zhang); Methodology, Y.Z.; Project administration, X.Z. (Xuhui Zhao); Supervision, Y.Z., Y.T. and X.Z. (Xuhui Zhao); Writing—original draft, G.W. and D.L.; Writing一review and editing, Y.T. All authors have read and agreed to the published version of the manuscript.

Funding: This research was funded by National Key Research and Development Program of China name of funder [2017YFB0307500].

Conflicts of Interest: The authors declare no conflict of interest.

\section{References}

1. Song, B.; Zhang, X.Y.; Jin, L.H. Effect on rare-earth element lanthanum for bond strength of electrodeposited nickel. J. Rare Earths 2004, 22, 64-67.

2. Xing, X.G.; Wang, H.F.; Lu, P.N.; Han, Z.J. Influence of rare earths on electrochemical corrosion and wear resistance of RE-Cr/Ti pack coatings on cemented 304 stainless steel. Surf. Coat. Technol. 2016, 291, 151-160. [CrossRef]

3. Dong, X.L.; Wang, D.R.; Zeng, Y.Q. Effect of mechanical attrition on microstructure and properties of electro-deposition coatings on Nd-Fe-B. J. Rare Earths 2014, 32, 867. [CrossRef] 
4. Han, Z.Z.; Zuo, Y.; Ju, P.F.; Tang, Y.M.; Zhao, X.H.; Tang, J.L. The preparation and characteristics of a rare earth/nano- $\mathrm{TiO}_{2}$ composite coating on aluminum alloy by brush plating. Surf. Coat. Technol. 2012, 206, 3264-3269. [CrossRef]

5. Li, L.; Qu, Q.; Fang, Z.W.; Lin, W.; He, Y.; Yuan, R.; Ding, Z. Enhanced corrosion resistance of AZ31B magnesium alloy by cooperation of rare earth cerium and stannate conversion coating. Int. J. Electrochem. Sci. 2012, 7, 12690-12705.

6. Liu, C.; Revilla, R.I.; Liu, Z.Y.; Li, X.G.; Zhang, D.W.; Terryn, H. Effect of inclusions modified by rare earth elements (Ce, La) on localized marine corrosion in Q460NH weathering steel. Corros. Sci. 2017, 129, 82-90. [CrossRef]

7. Zhang, Z.Y.; Lu, X.C.; Han, B.L.; Luo, J.B. Rare earth effect on microstructure, mechanical and tribological properties of Co-Cr-W coatings. Mater. Sci. Eng. A 2007, 444, 92-98. [CrossRef]

8. Jin, G.; Lu, B.W.; Cui, X.F.; Song, J.H.; Liu, E.B. Influence of rare earths addition on residual stress of Fe-based coating prepared by brush plating technology. J. Rare Earths 2016, 34, 336. [CrossRef]

9. Ibrahim, M.A.M.; Bakdash, R.S. New non-cyanide acidic copper electroplating bath based on glutamate complexing agent. Surf. Coat. Technol. 2015, 282, 139-148. [CrossRef]

10. An, S.; Kim, Y.; Jo, H.S.; Kim, M.W.; Lee, M.W.; Yarin, A.L.; Yoon, S.S. Silver-decorated and palladium-coated copper electroplated fibers derived from electrospun polymer nanofibers. Chem. Eng. J. 2017, 327, 336-342. [CrossRef]

11. Ricky, A.; Cian, Ó.M.; James, F.R. Palladium Activated Self-Assembled Monolayer for Magnetics on Silicon Applications. Phys. Proc. 2015, 75, 1207-1213.

12. Tang, J.L.; Zuo, Y. Study on corrosion resistance of palladium films on 316L stainless steel by electroplating and electroless plating. Corros. Sci. 2008, 10, 2873-2878. [CrossRef]

13. Ju, P.F.; Zuo, Y.; Tang, J.L.; Tang, Y.M.; Han, Z.Z. The preparation of Pd-Ni/Pd-Cu double coatings on 316L stainless steel and the corrosion resistance in stirred boiling acetic and formic acids mixture. Mater. Chem. Phys. 2014, 144, 263-271. [CrossRef]

14. Zhang, H.Z.; Li, Y.; Zuo, Y.; Zhao, X.H.; Tang, Y.M. Electrodeposition of multi-layer Pd-Ni coatings on 316L stainless steel and their corrosion resistance in hot sulfuric acid solution. Trans. Nonferrous Met. Soc. China 2017, 27, 1543-1550. [CrossRef]

15. Jiang, B.Q.; Huang, Q.R.; Peng, J.; Zhang, H.; Zhang, S.Y.; Wang, M.W. Stimulation of rare earths in quartz optical fiber surface metallization by electroless plating and electroplating. J. Rare Earth 2007, 25, 426.

16. Fu, C.Q.; Yong, F.; Wang, S.Y.; Wang, Z.; Zhang, Q.L.; Luo, X.L. Effect of rare element cerium on the morphology and corrosion resistance of electro-less Ni-P coatings. MATEC Web. Conferences. EDP Sci. 2015, 35. [CrossRef]

17. Liu, G.C.; Huang, Z.X.; Wang, L.D.; Sun, W.; Wang, S.L.; Deng, X.L. Effects of Ce ${ }^{4+}$ on the structure and corrosion resistance of electroless deposited Ni-Cu-P coating. Surf. Coat. Technol. 2013, 222, 25-30. [CrossRef]

18. Wasekar, N.P.; Haridoss, P.; Seshadri, S.K.; Sundararajan, G. Influence of mode of electrodeposition, current density and saccharin on the microstructure and hardness of electrodeposited nanocrystalline nickel coatings. Surf. Coat. Technol. 2016, 291, 130-140. [CrossRef]

19. Wang, D.; Cheng, Y.F.; In, H.M.; Zhang, J.Q.; Gao, J.G. Influence of $\mathrm{LaCl}_{3}$ addition on microstructure and properties of nickel-electroplating coating. J. Rare Earths 2013, 31, 209. [CrossRef]

20. Li, Y.D.; Li, G.S.; Jiang, H.; Li, B.J. Study of a new type of matrix material for electroplated diamond tools. Key Eng. Mater. 2003, 250, 89-93. [CrossRef]

21. Xu, L.; Zuo, Y.; Tang, J.L.; Tang, Y.M.; Ju, P.F. Chromium-Palladium films on 316L stainless steel by pulse electrodeposition and their corrosion resistance in hot sulfuric acid solutions. Corros. Sci. 2011, 53, 3788-3795. [CrossRef]

(C) 2020 by the authors. Licensee MDPI, Basel, Switzerland. This article is an open access article distributed under the terms and conditions of the Creative Commons Attribution (CC BY) license (http://creativecommons.org/licenses/by/4.0/). 